\title{
RESEARCH
}

Open Access

\section{Factors related to health-related quality of life in ankylosing spondylitis, overall and stratified by sex}

Lucy Law ${ }^{1}$, Jeanette Beckman Rehnman ${ }^{1}$, Anna Deminger², Eva Klingberg², Lennart T. H. Jacobsson² and Helena Forsblad-d'Elia ${ }^{1,2^{*}}$ (D)

\begin{abstract}
Background: Ankylosing spondylitis (AS) begins early in life and often leads to reduced physical function, but less is known about the impacts it has on health-related quality of life (HRQoL). The aims of this study were to assess HRQoL using the Short Form-36 (SF-36) in a cohort of patients with AS compared with controls and to examine associations between SF-36 scores and spinal radiographic changes, physical function, disease activity and demographic data overall and stratified by sex.

Methods: A cohort of patients with AS from Western Sweden were assessed using the Modified Stoke Ankylosing Spondylitis Spine Score (mSASSS) with spinal radiographs, clinical examination and questionnaires, including the Bath Ankylosing Spondylitis Metrology Index, Bath Ankylosing Spondylitis Functional Index (BASFI), Ankylosing Spondylitis Disease Activity Score-C-reactive protein (ASDAS-CRP), Bath Ankylosing Spondylitis Disease Activity Index, Bath Ankylosing Spondylitis Patient Global (BASG) and SF-36. Each patient's SF-36 results were compared with those of five age-matched and sex-matched persons $(n=1055)$ from the SF-36 Swedish normative population database. Associations between SF-36 physical component summary (PCS) and mental component summary (MCS) scores and disease-related and demographic factors were investigated using univariate and multivariable ogistic regression analyses with PCS and MCS below/above their respective median values as dependent variables.
\end{abstract}

Results: A total of 210 patients, age (median, IQR) 49.0 (21.2) years, symptom duration 24.0 (21.0) years, men 57.6\% and HLAB27 87.1\% were included. Patients with AS scored significantly lower $(p<0.001)$ compared to controls in all SF-36 domains and component summaries; PCS 42.4 (14.5) in AS versus 52.4 (11.8) in controls and MCS 47.9 (20.0) in AS versus 54.1 (10.1) in controls. Both men and women scored significantly lower in PCS compared with MCS. Multivariable logistic regression analyses revealed that living without a partner (OR 2.38, 95\% Cl 1.00-5.67), long symptom duration (year in decade OR 1.66, 95\% Cl 1.16-2.37), higher BASFI (OR 1.98, 95\% Cl 1.46-2.70) and ASDAS $\geq$ 2.1 (OR 3.32, 95\% Cl 1.45-7.62) were associated with worse PCS, while living without a partner (OR 3.04, 95\% Cl 1.346.91), fatigue (visual analogue scale for global fatigue greater than the median (OR 6.36, 95\% Cl 3.06-13.19) and ASDAS $\geq 2.1$ (OR 2.97, 95\% Cl 1.41-6.25) with worse MCS. Some differences between sexes were observed in the results.

(c) The Author(s). 2018 Open Access This article is distributed under the terms of the Creative Commons Attribution 4.0 International License (http://creativecommons.org/licenses/by/4.0/), which permits unrestricted use, distribution, and reproduction in any medium, provided you give appropriate credit to the original author(s) and the source, provide a link to the Creative Commons license, and indicate if changes were made. The Creative Commons Public Domain Dedication waiver (http://creativecommons.org/publicdomain/zero/1.0/) applies to the data made available in this article, unless otherwise stated. 


\begin{abstract}
(Continued from previous page)
Conclusions: The patients with AS had significantly lower HRQoL compared with controls. PCS was more affected compared to MCS in both sexes. Both disease-related and demographic factors were associated with HRQoL, partly overlapping for PCS and MCS. Factors associated with HRQoL showed some differences between sexes. By modifying factors, such as ASDAS-CRP and fatigue, HRQoL may potentially be improved.
\end{abstract}

Trial registration: ClinicalTrials.gov, NCT00858819. Registered on 9 March 2009. Last updated on 28 May 2015.

Keywords: Ankylosing spondylitis, Health-related quality of life, Medical outcome survey short form-36, Disease activity, Fatigue, Cross-sectional study, Observational study

\section{Background}

Ankylosing spondylitis (AS) is a chronic inflammatory rheumatic disease primarily affecting the sacroiliac joints and spine [1]. Inflammation of the spinal structures and progressive spinal changes in the vertebrae and surrounding tissue, is largely responsible for the decreased physical function and mobility experienced by patients with AS [2]. Studies of AS often describe functional disabilities and measures of disease activity, however, they less often report the quality of life experienced by patients with AS and how this is related to AS disease characteristics. Health-related quality of life (HRQoL) is a multi-dimensional concept including not only a person's physical wellbeing, but also a person's mental health and physical ability, both as an individual and as a participating member of the community. The Medical Outcome Survey Short Form-36 (SF-36) was designed for use in clinical practice and research, health policy evaluations, and general population surveys and is utilised in many different countries [3-6]. Yang et al. recently performed a meta-analysis based on of 38 studies assessing HRQoL using the SF-36 in patients with AS and found that they had significantly worse HRQoL compared to persons from general populations and that to measure HRQoL should be regarded as an essential part of the overall assessment of patients with AS [7]. The SF-36 is grouped into eight domains reflecting physical and mental health and two summary scores, a physical component summary (PCS) and a mental component summary (MCS) score. Yang et al. reported that pooled mean scores ranged from 45.9 to 58.2 in the physical health domains and from 47.5 to 62.5 in the mental health domains in their meta-analysis of patients with AS [7] as compared to 72.5 to 85.2 and 60.0 to 84.6 , respectively, in the normative general population database from Norway, one of the databases used for comparison with AS [8]. The Bath Ankylosing Spondylitis Disease Activity Index (BASDAI) and Bath Ankylosing Spondylitis Functional Index (BASFI) have been found to be negatively associated with some domains of the SF-36 [7, 9-13]. The relationship between HRQoL, laboratory markers of inflammation, the Ankylosing Spondylitis Disease Activity Score (ASDAS), Bath Ankylosing Spondylitis Metrology Index
(BASMI) and spinal radiographic changes, as assessed by the modified Stoke Ankylosing Spondylitis Spinal Score (mSASSS), is less studied. Since the AS phenotype differs between sexes, with men generally displaying more AS spinal radiographic changes compared to women, it is of importance to investigate factors related to $\mathrm{HRQoL}$ overall and also stratified by sex to be able to better personalize the care of patients with AS $[14,15]$.

The objectives of this study were to investigate the following in patients with AS: (1) HRQoL assessed by the SF-36 compared with HRQoL in controls from the general population, (2) HRQoL in relation to age and (3) to examine associations between the SF-36 scores and spinal radiographic changes, physical function, mobility, disease activity and demographic data overall and stratified by sex.

\section{Methods}

\section{Patients and controls}

Patients were recruited from three sites in Western Sweden $[14,16]$. This cross-sectional study focuses on HRQoL assessed by the SF-36 questionnaire. The inclusion criteria for the study were a diagnosis of AS according to the modified New York criteria [17] and age $\geq 18$ years. The exclusion criteria were difficulties in understanding the Swedish language, dementia and pregnancy. Patients with psoriasis or inflammatory bowel disease (IBD) were also excluded in order to create a more homogenous cohort of patients with typical AS. All patients with AS meeting the study criteria were invited to participate and of these, 211 patients were initially included.

Results of the SF-36 questionnaires completed by the patients with AS $(n=211)$ were compared to those of five age-matched and sex-matched persons, per AS patient $(n=1055)$, randomly drawn from the SF-36 Swedish normative population database [5]. One of the included patients was later found to have psoriasis and was excluded from further analysis, leaving 210 patients to take part in this study. Figure 1 summarises the process of patient inclusion.

This study was approved by the Regional ethical committee at the University of Gothenburg, Sweden and 


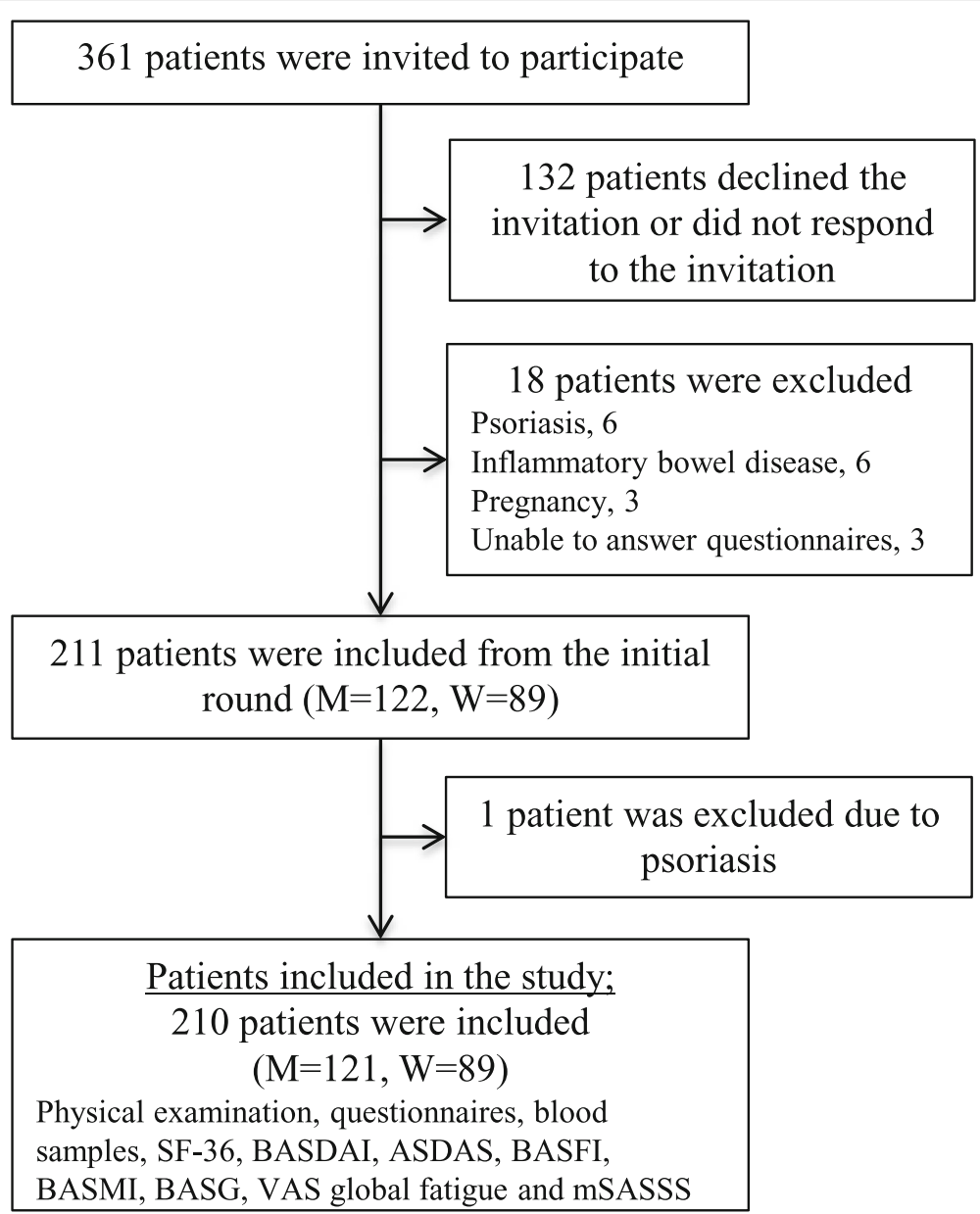

Fig. 1 Process of inclusion of the patients with ankylosing spondylitis. M, men; W, women; BASDAl, Bath Ankylosing Spondylitis Disease Activity Index; ASDAS, Ankylosing Spondylitis Disease Activity Score; BASFI, Bath Ankylosing Spondylitis Functional Index; BASMl, Bath Ankylosing Spondylitis Metrology Index; BAS-G, Bath Ankylosing Spondylitis Patient Global; VAS, visual analogue scale; mSASSS, modified Stoke Ankylosing Spondylitis Spinal Score

was performed in accordance with the Declaration of Helsinki.

\section{The SF-36 questionnaire}

HRQoL was assessed using the self-reported SF-36 questionnaire, an instrument consisting of 36 questions grouped into eight domains [3-6]. The eight domains include physical functioning (PF; 10 items), role physical (RP; 4 items), bodily pain (BP; 2 items), general health (GH; 5 items), vitality (VT; 4 items), social functioning (SF; 2 items), role emotional (RE; 3 items) and mental health (MH; 5 items). In addition, a further single item concerns reported health transition over the past year. The response alternatives for the role limitation domains (physical and emotional) are dichotomous (yes/no), and the other items have three to six response choices. The items within each domain contribute to an overall domain score between 0 and 100 , with 0 representing worst and 100 excellent health. The questions reflect the individuals' health status during the last 4 weeks. The eight domains are also combined to produce two summary scores. The first four aforementioned domains, PF, $\mathrm{RP}, \mathrm{BP}$ and $\mathrm{GH}$, give an overall physical component summary (PCS) score and the second four domains, VT, $\mathrm{SF}, \mathrm{RE}$ and $\mathrm{MH}$, give an overall mental component summary (MCS) score. The component summary scores are standardised combined scores, with a mean of 50 and standard deviation of 10 .

\section{Other questionnaires}

Participants also answered additional questionnaires including the BASDAI and the BASFI. The BASDAI estimates the patient's disease activity and the BASFI estimates the functional limitations during the last week. Higher values indicate higher disease activity and respectively worse physical function [18].

The Ankylosing Spondylitis Disease Activity Score, including C-reactive protein (ASDAS-CRP), was calculated 
for each patient. The disease activity is divided into inactive disease (ASDAS $<1.3$ ), low disease activity $(1.3 \leq$ ASDAS $<2.1)$, high disease activity $(2.1 \leq$ ASDAS $\leq 3.5)$ and very high disease activity (ASDAS > 3.5) $[18,19]$. The patients also answered the Bath Ankylosing Spondylitis Patient Global (BAS-G) [18]. A visual analogue scale (VAS) for global fatigue was used to evaluate fatigue experienced over the last few days graded from not at all (0) to extreme fatigue (100). In addition, the patients answered a questionnaire about lifestyle habits, medical history and medication.

\section{Physical examination}

The patients' mobility was measured using the BASMI. A higher BASMI score indicates less spinal mobility [18]. Physical examinations were performed by one physician (EK).

\section{Radiography}

Spinal radiographic changes were assessed from the lateral projection of the spinal radiographs and were graded using the mSASSS. Anterior corners of vertebra $\mathrm{C} 2-\mathrm{T} 1$ and $\mathrm{T} 12-\mathrm{S} 1$ were graded with a score between 0 and $3(0=$ normal, $1=$ erosion, sclerosis or squaring, $2=$ syndesmophyte, $3=$ bridging syndesmophyte). The overall scoring scale ranges from 0 to 72 , with 72 representing complete ankylosis [20]. To have a mSASSS $\geq 2$ at a vertebral corner was classified as having a syndesmophyte. Severe spinal radiographic change was defined as $\geq 3$ consecutive intervertebral bridges in the cervical spine and/or the lumbar spine, similar to the definition of grade $4=$ severe in the Bath Ankylosing Spondylitis Radiology Index (BASRI) [21]. The majority of $x$-rays were performed within a couple of months after the study inclusion and $<5 \%$ of the patients were examined up to 6 months after the inclusion. One experienced radiologist scored all radiographs.

\section{Laboratory tests}

Erythrocyte sedimentation rate (ESR) and C-reactive protein (CRP) were analysed consecutively by standard laboratory techniques at the different hospitals.

\section{Statistics}

Non-parametrical statistical tests were applied because not all data were normally distributed. The median, 25th percentile $(\mathrm{Q} 1)$ and 75th percentile $(\mathrm{Q} 3)$ or interquartile range (IQR) or mean with standard deviation (SD) were presented for continuous data and frequency with percentage for categorical data. Data were compared using the MannWhitney $U$ test or chi square test, as appropriate. The Kruskal-Wallis test was used to compare multiple groups and the Mann-Whitney $U$ test was applied for post hoc analyses with a Bonferroni-corrected $p$ value $(<0.008)$.
Univariate logistic regression analyses were conducted with dichotomised PCS and MCS below (coded 1) and above (coded 0 ) their respective median values as dependent variables and demographic and disease-related variables of interest as covariates. Age and symptom duration were stratified into decades and BASMI and BASFI into whole units. BASDAI was dichotomised into $\geq 4$ (coded 1$)$ and $<$ 4 (coded 0$)$ and ASDAS-CRP into $\geq 2.1$ (coded 1$)$ and $<2.1$ (coded 0 ). mSASSS 1 was log-transformed in order to improve the distribution. Variables with $p$ values $\leq 0.2$ in the univariate analyses (Additional file 1: Tables S4 and S5) were chosen first to potentially be entered into the multivariable logistic regression models, the enter method. Thereafter, variables were excluded if the variable of interest by definition was a part of another variable, for instance, ASDAS-CRP was chosen as a variable reflecting disease activity instead of the BASDAI and CRP. The BASG was excluded as the ASDAS-CRP was chosen. The VAS for global fatigue was chosen instead of the BASDAI. The remaining variables were thereafter checked for multicollinearity and variables with the lowest $p$ value in the univariate analysis were kept and entered into the multivariable models. In the multivariable logistic regression analyses, PCS and MCS were dichotomised as described above and were the dependent variables, while the other variables formed the independent variables (Tables 2 and 3). A $p$ value $<0.05$ was considered statistically significant. All statistical analyses were performed using SPSS version 24 (SPSS Inc., IBM, Chicago, USA).

\section{Results}

For the enrolment process see Fig. 1. A total of 210 patients with AS, 121 (57.6\%) men and 89 (42.4\%) women, with a median age of 49.0 years $(40.0,61.2)$ and a median symptom duration of 24.0 years $(13.0,34.0)$, were included in this report. HLA-B27 was present in 183 (87.1\%) of the patients with AS. The mSASSS median and mean values were $5.0(0.0,20.0)$ and $13.9 \pm 19.0$, respectively. Concerning biological drugs, 43 (20.5\%) patients were treated with a TNF-inhibitor (TNFi) out of which 32 (15.2\%) were used in combination with a conventional synthetic disease modifying anti-rheumatic drug (csDMARD). In total, 73 (34.8\%) patients were on a TNFi and/or a csDMARD. Characteristics of all the patients and stratified by sex are displayed in Table 1. Comparisons between men and women showed that the age and symptom duration did not differ significantly between sexes. Women with AS had a significantly higher ESR and VAS for global fatigue compared to the men. Men with AS had significantly higher mSASSS and body mass index (BMI) than the women. More men carried HLA-B27 and had $\geq 1$ prevalent syndesmophyte compared to the women. Only men had severe radiographic changes in the spine, defined as $\geq$ 3 consecutive intervertebral bridges in the cervical spine 
Table 1 Characteristics of the patients with ankylosing spondylitis, overall and stratified and compared by sex

\begin{tabular}{|c|c|c|c|c|}
\hline Variables & All, $n=210$ & Men, $n=121$ (57.6) & Women, $n=89$ (42.4) & $P$ value \\
\hline Age, years & $49.0(40.0,61.2)$ & $49.0(39.5,61.0)$ & $49.0(41.5,62.0)$ & 0.48 \\
\hline $\mathrm{BMI}, \mathrm{kg} / \mathrm{m}^{2}$ & $25.2(22.8,28.4)$ & $25.8(23.6,28.9)$ & $24.0(21.8,27.5)$ & 0.003 \\
\hline Civil state: single & $58(27.6)$ & $34(28.1)$ & $24(27.0)$ & 0.86 \\
\hline in a relationship & $152(72.4)$ & $87(71.9)$ & $65(73.0)$ & 0.87 \\
\hline Years in school: $<13$ & $98(46.9)^{\mathrm{a}}$ & $62(51.7)^{\mathrm{a}}$ & $36(40.4)$ & 0.11 \\
\hline$\geq 13$ years & $111(53.1)$ & $58(48.3)$ & $53(59.6)$ & 0.11 \\
\hline Ever smoker & $105(50.0)$ & $65(53.7)$ & $40(44.9)$ & 0.21 \\
\hline VAS global fatigue, score & $59.0(27.0,74.0)$ & $50.0(20.5,68.0)$ & $64.0(42.5,76.0)$ & 0.002 \\
\hline Duration of symptoms, years & $24.0(13.0,34.0)^{c}$ & $23.0(13.0,33.0)^{\mathrm{b}}$ & $24.0(12.5,34.0)^{\mathrm{a}}$ & 0.80 \\
\hline Duration of disease, years & $12.0(5.0,23.0)^{\mathrm{a}}$ & $12.5(6.0,24.0)^{\mathrm{a}}$ & $11.0(4.0,18.5)$ & 0.11 \\
\hline $\mathrm{ESR}, \mathrm{mm} / \mathrm{h}$ & $11.0(7.0,19.0)$ & $10.0(5.0,17.0)$ & $14.0(10.0,22.5)$ & 0.001 \\
\hline CRP, mg/L & $3.0(1.0,7.0)^{\mathrm{a}}$ & $3.0(1.0,7.0)^{\mathrm{a}}$ & $2.0(1.0,7.5)$ & 0.38 \\
\hline HLA-B27 positive & $183(87.1)$ & $112(92.6)$ & $71(79.8)$ & 0.006 \\
\hline History of anterior uveitis & $108(51.5)$ & $69(57.0)$ & $39(43.8)$ & 0.058 \\
\hline TNFi and/or CsDMARD & $73(34.8)$ & $45(37.2)$ & $28(31.5)$ & 0.39 \\
\hline BASMI, score & $3.0(2.0,4.0)$ & $3.0(1.8,4.3)$ & $2.8(2.2,3.8)$ & 0.34 \\
\hline BASFI, score & $2.3(1.0,3.8)^{c}$ & $2.3(1.0,3.7)^{\mathrm{a}}$ & $2.3(1.0,4.2)^{\mathrm{b}}$ & 0.73 \\
\hline BASDAl, score & $3.5(1.7,5.3)^{d}$ & $2.9(1.5,5.2)^{c}$ & $3.7(1.9,5.6)^{\mathrm{a}}$ & 0.079 \\
\hline ASDAS-CRP, score & $2.1(1.4,2.9)^{\mathrm{a}}$ & $2.0(1.3,2.9)^{\mathrm{a}}$ & $2.2(1.5,2.8)$ & 0.70 \\
\hline BAS-G, score & $2.90(1.15,5.45)$ & $2.6(1.0,5.0)$ & $3.5(1.3,5.7)$ & 0.28 \\
\hline mSASSS, score & $5.0(0.0,20.0)$ & $8.0(2.0,34.0)$ & $2.0(0.0,9.5)$ & $<0.001$ \\
\hline Syndesmophyte and/or & $98(46.7)$ & $71(58.7)$ & $27(30.3)$ & $<0.001$ \\
\hline$\geq 3$ intervertebral bridges consecutively, cervical and/or lumbar spine & $29(13.8)$ & $29(24)$ & 0 & $<0.001$ \\
\hline \multirow[t]{2}{*}{ PF, score } & $80.0(65.0,90.0)$ & $80.0(69.4,90.0)$ & $75.0(60.6,90.0)$ & 0.023 \\
\hline & $74.4 \pm 21.4$ & $76.7 \pm 21.5$ & $71.2 \pm 21.0$ & \\
\hline \multirow[t]{2}{*}{ RP, score } & $75.0(25.0,100.0)$ & $75.0(25.0,100.0)$ & $75.0(0.0,100.0)$ & 0.12 \\
\hline & $59.3 \pm 41.1$ & $63.1 \pm 40.3$ & $54.2 \pm 41.8$ & \\
\hline \multirow[t]{2}{*}{$B P$, score } & $51.0(41.0,64.0)$ & $51.0(41.0,72.0)$ & $51.0(41.0,62.0)$ & 0.19 \\
\hline & $54.1 \pm 21.9$ & $55.8 \pm 22.8$ & $51.7 \pm 20.4$ & \\
\hline \multirow[t]{2}{*}{ GH, score } & $62.0(40.0,77.0)$ & $62.0(40.0,77.0)$ & $60.0(40.0,76.0)$ & 0.78 \\
\hline & $57.1 \pm 22.8$ & $56.6 \pm 23.7$ & $57.7 \pm 21.8$ & \\
\hline \multirow[t]{2}{*}{ VT, score } & $50.0(30.0,70.0)$ & $55.0(30.0,75.0)$ & $50.0(30.0,65.0)$ & 0.010 \\
\hline & $50.6 \pm 23.6$ & $54.3 \pm 24.1$ & $45.5 \pm 22.0$ & \\
\hline \multirow[t]{2}{*}{ SF, score } & $75.0(65.2,100.0)$ & $87.5(62.5,100.0)$ & $75.0(62.5,100.0)$ & 0.10 \\
\hline & $75.8 \pm 25.0$ & $77.7 \pm 25.6$ & $73.3 \pm 24.1$ & \\
\hline \multirow[t]{2}{*}{ RE, score } & $100.0(33.3,100.0)^{b}$ & $100.0(33.3,100.0)^{\mathrm{a}}$ & $100.0(33.3,100.0)^{a}$ & 0.16 \\
\hline & $68.8 \pm 40.8^{b}$ & $71.9 \pm 39.8^{\mathrm{a}}$ & $64.4 \pm 41.9^{\mathrm{a}}$ & \\
\hline \multirow[t]{2}{*}{ MH, score } & $76.0(63.0,88.0)$ & $76.0(64.0,88.0)$ & $72.0(60.0,84.0)$ & 0.039 \\
\hline & $71.9 \pm 19.8$ & $73.7 \pm 20.7$ & $69.5 \pm 18.3$ & \\
\hline \multirow[t]{2}{*}{ PCS, score } & $42.4(34.3,48.7)^{b}$ & $43.6(35.4,49,4)^{a}$ & $41.8(32.6,47.5)^{\mathrm{a}}$ & 0.16 \\
\hline & $41.4 \pm 10.0^{b}$ & $42.1 \pm 10.0^{\mathrm{a}}$ & $40.4 \pm 10.2^{\mathrm{a}}$ & \\
\hline \multirow[t]{2}{*}{ MCS, score } & $48.0(35.6,55.2)^{b}$ & $49.2(39.9,56.1)^{a}$ & $46.0(33.4,53.8)^{\mathrm{a}}$ & 0.13 \\
\hline & $44.8 \pm 12.5^{b}$ & $45.9 \pm 12.3^{\mathrm{a}}$ & $43.3 \pm 12.8^{\mathrm{a}}$ & \\
\hline
\end{tabular}

Values are median and 25th percentile (Q1) and 75th percentile (Q3), numbers of patients and percent (\%) or mean \pm SD. Comparisons between men and women are assessed by Mann-Whitney U-test or Chi-square test. Significant differences are in bold text

$B M I$ body mass index, VAS visual analogue scale, ESR erythrocyte sedimentation rate, CRP C-reactive protein, TNFi TNF inhibitor, csDMARD conventional synthetic disease modifying anti-rheumatic drug, BASMI Bath Ankylosing Spondylitis Metrology Index, BASFI Bath Ankylosing Spondylitis Functional Index, BASDAI Bath Ankylosing Spondylitis Disease Activity Index, ASDAS-CRP Ankylosing Spondylitis Disease Activity Score-CRP, BAS-G Bath Ankylosing Spondylitis Patient Global, mSASSS Modified Stoke Ankylosing Spondylitis Spine Score, PF physical function, RP role physical, BP bodily pain, GH general health, VT vitality, SF social function, RE role emotional, $M H$ mental health, $P C S$ physical component summary, MCS mental component summary

Number of missing data values: ${ }^{a} n=1 ;{ }^{b} n=2 ;{ }^{c} n=3 ;{ }^{d} n=4$ 
and/or the lumbar spine. Otherwise, baseline characteristics were similar between sexes.

\section{Health related quality of life in patients with ankylosing spondylitis and in the general population}

The patients with AS had significantly lower SF-36 scores in all domains and the component summary scores, PCS and MCS, when compared to five age-matched and sex-matched controls from the general population per AS patient $(p<0.001)$ (Fig. 2a, Additional file 1: Table S1). The mean PCS score \pm SD was $41.3 \pm 10.1$ in AS versus $49.1 \pm$ 9.8 in controls and the mean MCS score was $44.6 \pm 12.7$ in AS versus $50.5 \pm 10.4$ in controls. The mean age \pm SD was $50.1 \pm 12.9$ years in the patients with AS versus $50.1 \pm 12.8$ years in the controls, and the sex-distribution was exactly the same, due to the matched selection of controls.
Comparison of SF-36 physical domain scores between sexes in AS showed that women had a significantly lower PF score compared to men $(p=0.023)$. Regarding the mental domains, women had significantly lower VT and $\mathrm{MH}$ scores compared to men $(p=0.010$ and $p=$ 0.039 , respectively) (Fig. $2 \mathrm{~b}$, Table 1 ). No significant differences were found in PCS or MCS between men and women with AS. PCS was significantly lower compared with MCS in the total AS group $(p<0.001)$, a difference also seen in both women and men in the sex-stratified analyses ( $p=0.027$ and $p=0.002$ respectively) (Fig. 2b).

\section{Health-related quality of life in relation to age}

The patients were divided into four different age groups: $\leq 40$ years $(n=53), 41-50$ years $(n=57), 51-60$ years $(n$ $=44)$ and $\geq 61$ years $(n=56)$, in order to study the

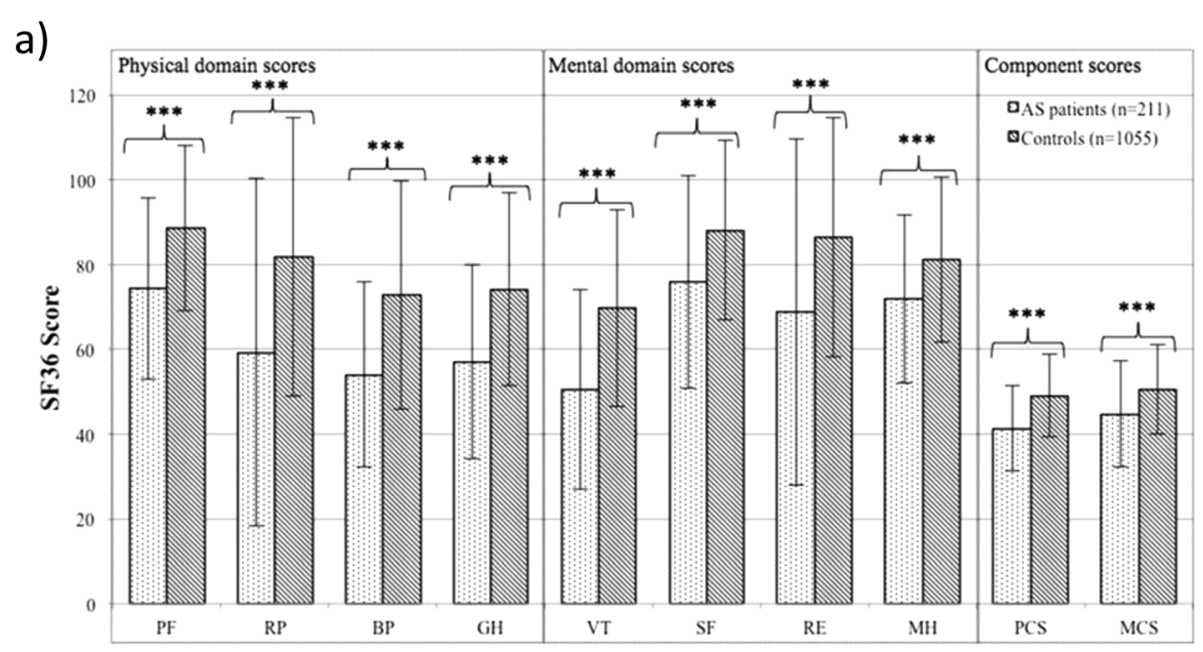

b)

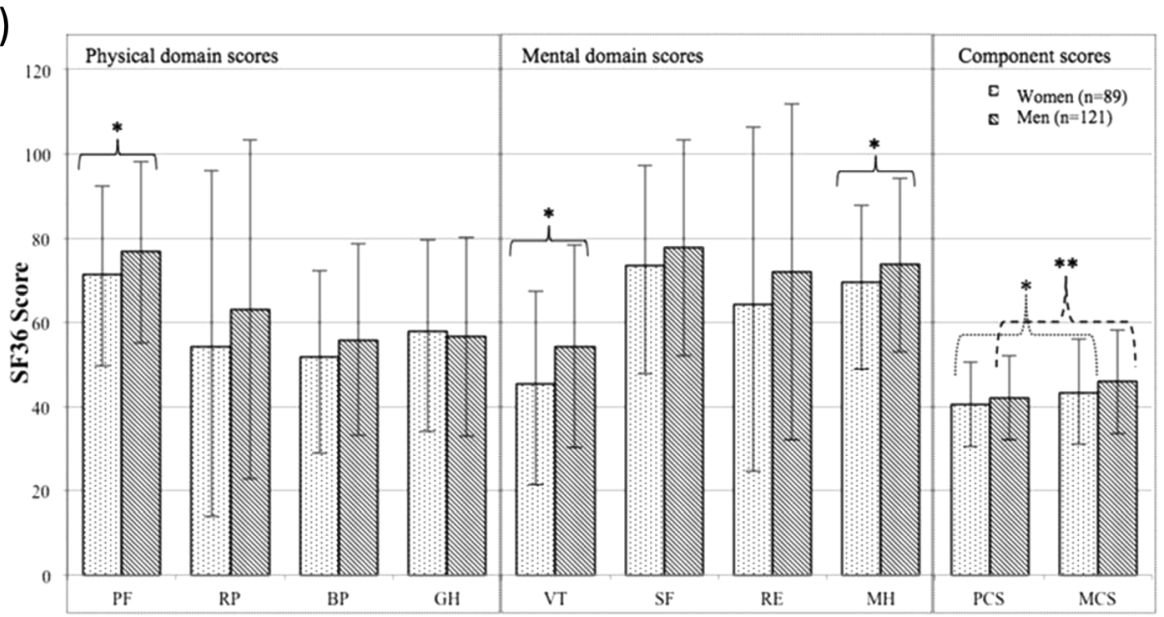

Fig. 2 Short form-36 (SF-36) in 211 patients with ankylosing spondylitis (AS) compared to 1055 age-matched and sex-matched controls from the general population (a) and 210 patients with AS, stratified by sex (b). Mean \pm SD are shown. physical component summary (PCS) and mental component summary (MCS) are standardized scores with a mean of 50 and SD of 10. The other domains score between 0 and 100 with $0=$ worst and 100 = best health. PF, physical function; RP, role physical; BP, bodily pain; GH, general health; VT, vitality; SF, social function; RE, role emotional; MH, mental health. Mann-Whitney $U$ test and Wilcoxon rank sum tests were used for comparisons; ${ }^{*} p<0.05,{ }^{* *} p<0.01,{ }^{* *^{*}} p<0.001$ 
impact of age on the SF-36 summary scores. There was a difference in the PCS score between the four age groups $(p<0.001)$, and post hoc analysis showed that the PCS score was significantly lower in the age group $\geq$ 61 years compared to the age group $\leq 40$ years ( $p<$ 0.001). No difference in the MCS score between the 4 age groups was found, Fig. 3. Correlation analyses revealed an inverse association between PCS score and age $\left(r_{\mathrm{s}}=-0.29, p<0.001\right)$, and when stratified by sex, there was significant association in men $\left(r_{\mathrm{s}}=-0.34, p<0.001\right)$ and a trend in women $\left(r_{\mathrm{s}}=-0.20, p=0.066\right)$. There was no significant correlation between MCS and age.

\section{Comparison between patients with ankylosing spondylitis} with higher and lower health-related quality of life scores The patients were divided into groups according to the median values of PCS and MCS scores and different characteristics were compared between patients with lower versus higher PCS and MCS scores. The comparisons were also performed stratified by sex. The results are shown in Additional file 1: Tables S2 and S3.

\section{Logistic regression analyses demonstrating factors} associated with worse health-related quality of life Univariate logistic regression analyses with PCS and MCS, below their respective median values, as dependent variables and demographic and disease-related factors as independent variables, overall and stratified by sex, are shown in Additional file 1: Tables S4 and S5.

The process for including variables into the multivariable regression analyses is described in "Methods". Multivariable logistic regression analyses showed that to live alone without a partner was a significant factor associated with a worse PCS score (OR 2.38, 95\% CI 1.005.67). To have a longer symptom duration (decades)
(OR 1.66, 95\% CI 1.16-2.37), higher BASFI (OR 1.98 per unit, 95\% CI 1.46-2.70) and ASDAS-CRP $\geq 2.1$ (OR 3.32 , 95\% CI 1.45-7.62) was also associated with a worse PCS score. The sex-stratified analyses revealed that, in men, the most important determinants for a worse PCS score were a high BASFI and an ASDAS-CRP $\geq 2.1$, compared to a high BASFI in women (Table 2). In men, to have severe spinal radiographic changes was associated with a worse PCS score in the univariate but not in the multivariable logistic regression analysis. In a sensitivity analysis, age in decades was inserted into the models instead of symptom duration in decades. Age in decades was not a significant factor in these models, thus symptom duration in decades was kept in the models according to the criteria described in "Methods".

To live alone (OR 3.04, 95\% CI 1.34-6.91), to have VAS global fatigue greater than the median value (OR 6.36, 95\% CI 3.06-13.19) and ASDAS-CRP $\geq 2.1$ (OR 2.97, 95\% CI 1.41-6.25), were significant determinants associated with a worse MCS score (Table 3). The sex-stratified analyses revealed that longer education, high fatigue, and no severe radiographic changes in men, and to live without a partner, have high fatigue and ASDAS-CRP $\geq 2.1$ in women were the most important determinants of a worse MCS score (Table 3). In sensitivity analysis, age in decades was inserted into the models but was not a significant factor and did not alter the models substantially and was therefore not used. There was no significant association between the mSASSS and the PCS or MCS in the univariate or multivariable logistic regression analyses. Further sensitivity analyses based on demographics, excluding disease-related variables, revealed that to live without a partner was still associated with both worse PCS and MCS scores, and age in decades was associated with a worse PCS score but not with a worse MCS score (Additional file 1: Table S6).

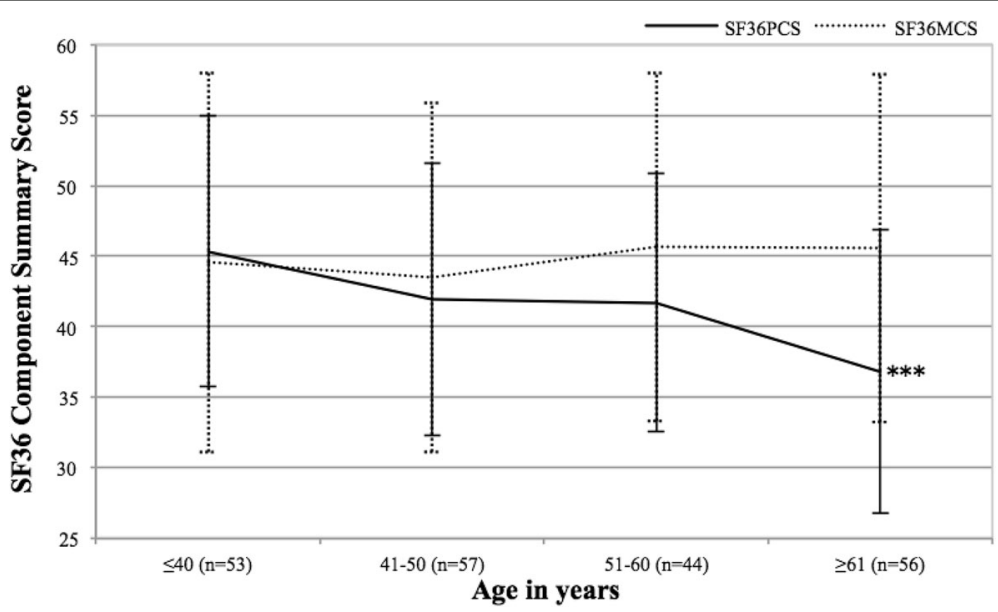

Fig. 3 Patients with ankylosing spondylitis $(n=210)$ divided in four age groups displaying Short Form-36 (SF-36) physical component summary (PCS) and mental component summary (MCS) scores. Mean \pm SD are shown; ${ }^{* *} p<0.001, n$, number of patients 
Table 2 Multivariable logistic regression analyses with PCS score below the median value as dependent variable

\begin{tabular}{|c|c|c|c|c|c|c|c|c|c|}
\hline \multirow[b]{2}{*}{ Variables } & \multicolumn{3}{|c|}{$\begin{array}{l}\text { All, } n=210 \\
\text { PCS }<\text { median PCS } 42.4\end{array}$} & \multicolumn{3}{|c|}{$\begin{array}{l}\text { Men, } n=121 \\
\text { PCS }<\text { median PCS } 43.6\end{array}$} & \multicolumn{3}{|c|}{$\begin{array}{l}\text { Women, } n=89 \\
\text { PCS }<\text { median PCS } 41.8\end{array}$} \\
\hline & OR & $95 \% \mathrm{Cl}$ & $P$ value & $\mathrm{OR}$ & $95 \% \mathrm{Cl}$ & $P$ value & OR & $95 \% \mathrm{Cl}$ & $P$ value \\
\hline $\mathrm{BMl}, \mathrm{kg} / \mathrm{m}^{2}$ & 1.03 & 0.93 to 1.14 & 0.55 & 0.98 & 0.84 to 1.14 & 0.78 & & & \\
\hline Civil state, single & 2.38 & 1.00 to 5.67 & 0.049 & 3.28 & 0.94 to 11.52 & 0.063 & 3.07 & 0.83 to 11.40 & 0.094 \\
\hline Years in school, $<13$ years & 1.12 & 0.50 to 2.48 & 0.79 & 1.40 & 0.43 to 4.55 & 0.57 & & & \\
\hline Ever smoker & 0.77 & 0.35 to 1.73 & 0.53 & 0.55 & 0.16 to 1.89 & 0.34 & & & \\
\hline VAS global fatigue, > median & 1.04 & 0.46 to 2.38 & 0.92 & 2.23 & 0.66 to 7.56 & 0.20 & & & \\
\hline Duration of symptoms, decades & 1.66 & 1.16 to 2.37 & 0.005 & 1.36 & 0.81 to 2.30 & 0.24 & 1.69 & 0.99 to 2.90 & 0.055 \\
\hline ESR, > median & 0.98 & 0.45 to 2.10 & 0.95 & & & & & & \\
\hline BASMI, units & & & & & & & 0.72 & 0.38 to 1.34 & 0.30 \\
\hline Lateral spinal flexion, cm & 0.99 & 0.90 to 1.09 & 0.86 & 0.92 & 0.80 to 1.06 & 0.27 & & & \\
\hline BASFI, unit & 1.98 & 1.46 to 2.70 & $<0.001$ & 2.09 & 1.29 to 3.41 & 0.003 & 2.25 & 1.42 to 3.57 & 0.001 \\
\hline ASDAS-CRP, $\geq 2.1$ & 3.32 & 1.45 to 7.62 & 0.005 & 4.87 & 1.46 to 16.27 & 0.010 & 1.83 & 0.51 to 6.53 & 0.36 \\
\hline Log10mSASSS + 1, score & 0.74 & 0.36 to 1.54 & 0.43 & & & & & & \\
\hline$\geq 3$ intervertebral bridges consecutively (only men) ${ }^{a}$ & & & & 0.57 & 0.12 to 2.70 & 0.48 & & & \\
\hline
\end{tabular}

Significant differences are in bold text. The independent variables were defined by having a univariate association with PCS (p-value $\leq 0.2$ ) and not demonstrating collinearity. Due to some missing data, the models are based on an overall 203 patients and in stratified analyses 115 men and 86 women

$P C S$ physical component summary, OR odds ratio, $C l$ confidence interval, BMI body mass index, VAS visual analogue scale, ESR erythrocyte sedimentation rate, BASMI Bath Ankylosing Spondylitis Metrology Index, BASFI Bath Ankylosing Spondylitis Functional Index, ASDAS-CRP Ankylosing Spondylitis Disease Activity Score C-reactive protein, $m S A S S S$ Modified Stoke Ankylosing Spondylitis Spine Score ${ }^{a}$ Cervical and/or lumbar spine

\section{Discussion}

In this study, we have used the generic instrument SF-36 to evaluate HRQoL in a well-characterised cohort of patients with AS. The patients with AS had significantly lower HRQoL compared with controls. PCS was more affected compared to MCS in both sexes. Both diseaserelated and demographic factors were associated with HRQoL. Also, for the first time, to the best of our knowledge, we identified determinants of worse HRQoL separately in men and in women with AS and we found that the factors associated with HRQoL differed in part between the sexes.

We showed that the patients with AS had significantly lower SF-36 scores compared to 1055 age-matched and sex-matched controls from the general population. The patients with AS scored lower in all SF-36 domains and component summary scores. Our findings are in line with results from other countries in which SF-36 in AS

Table 3 Multivariable logistic regression analyses with MCS score below the median value as dependent variable

\begin{tabular}{|c|c|c|c|c|c|c|c|c|c|}
\hline \multirow[b]{2}{*}{ Variables } & \multicolumn{3}{|c|}{$\begin{array}{l}\text { All, } n=210 \\
\text { MCS }<\text { median MCS } 48.0\end{array}$} & \multicolumn{3}{|c|}{$\begin{array}{l}\text { Men, } n=121 \\
\text { MCS }<\text { median MCS } 49.2\end{array}$} & \multicolumn{3}{|c|}{$\begin{array}{l}\text { Women, } n=89 \\
\text { MCS }<\text { median MCS } 46.0\end{array}$} \\
\hline & OR & $95 \% \mathrm{Cl}$ & $P$ value & OR & $95 \% \mathrm{Cl}$ & -value & OR & $95 \% \mathrm{Cl}$ & $P$ value \\
\hline $\mathrm{BMI}, \mathrm{kg} / \mathrm{m}^{2}$ & 1.01 & 0.93 to 1.09 & 0.86 & & & & & & \\
\hline Civil state, single & 3.04 & 1.34 to 6.91 & 0.008 & 2.24 & 0.76 to $6-61$ & 0.14 & 13.21 & 2.13 to 81.96 & 0.006 \\
\hline Years in school, $<13$ years & & & & 0.36 & 0.13 to 0.96 & 0.042 & & & \\
\hline Ever smoker & 1.26 & 0.61 to 2.58 & 0.53 & & & & 1.35 & 0.38 to 4.76 & 0.64 \\
\hline VAS global fatigue, $>$ median & 6.36 & 3.06 to 13.19 & $<0.001$ & 7.73 & 2.63 to 22.76 & $<0.001$ & 17.29 & 3.82 to 78.23 & $<0.001$ \\
\hline Lateral spinal flexion, cm & 1.02 & 0.95 to 1.09 & 0.64 & & & & 0.94 & 0.81 to 1.10 & 0.44 \\
\hline BASFI, unit & 1.18 & 0.93 to 1.50 & 0.16 & 1.41 & 0.99 to 2.00 & 0.057 & 1.07 & 0.73 to 1.57 & 0.72 \\
\hline ASDAS-CRP, $\geq 2.1$ & 2.97 & 1.41 to 6.25 & 0.004 & 2.62 & 0.89 to 7.70 & 0.080 & 6.74 & 1.76 to 25.85 & 0.005 \\
\hline Log10mSASSS + 1, score & & & & & & & 1.17 & 0.29 to 4.66 & 0.82 \\
\hline$\geq 3$ intervertebral bridges consecutively (only men) ${ }^{a}$ & & & & 0.17 & 0.044 to 0.65 & 0.01 & & & \\
\hline
\end{tabular}

Significant differences are in bold text. The independent variables were defined by having a univariate association with MCS ( $p$-value $\leq 0.2)$ and not demonstrating collinearity. Due to some missing data, the models are based on overall 204 patients and in stratified analyses 117 men and 86 women

MCS mental component summary, OR odds ratio, Cl confidence interval, BMI body mass index, VAS visual analogue scale, BASFI Bath Ankylosing Spondylitis Functional Index, ASDAS-CRP Ankylosing Spondylitis Disease Activity Score C-reactive protein, mSASSS Modified Stoke Ankylosing Spondylitis Spine Score, ${ }^{a}$ Cervical and/or lumbar spine 
has been compared indirectly with results from the general population $[9,22-24]$ and with the meta-analysis by Yang et al. who compared SF-36 scores in AS using two normative general-population databases of the SF-36. They stated also that HRQoL in AS was lower than in type II diabetes mellitus, and comparable with rheumatoid arthritis [7]. Thus, these results underline the importance of taking HRQoL into consideration in the management of patients with AS.

Furthermore, we observed that the PCS score was more affected compared to the MCS score. This was noted in the whole cohort and also in men and in women analysed individually. Yang et al. reported a pooled mean PCS score of 37.5 and MCS score of 44.7 [7]. Our results were similar, with a mean PCS score \pm SD of $41.4 \pm 10.0$ and MCS score of $44.8 \pm 12.5(n=210)$. This suggests that AS has a larger impact on physical components of HRQoL compared to mental components, although both dimensions are reduced compared to the general population.

It is known that the phenotype of AS differs between the sexes. For instance, at a group level, men with AS have more AS-related spinal radiographic changes [25]. This finding is one reason why it could be hypothesized that there should be more effect on HRQoL in men than in women with AS. However, we found that the women with AS scored worse in two mental domains and one physical domain compared to the men with AS. Similar sex differences in SF-36 scores have been reported previously [22, 26, 27]. Interestingly, results from the SF-36 Swedish normative population database, consisting of 8930 persons from the general population in different parts of Sweden, showed a clear difference in mean scores between men and women, with women generally reporting lower HRQoL. This indicates a general phenomenon that women report worse HRQoL compared to men [4].

We also explored the impact of age on the PCS and MCS scores. Concerning the MCS, the median MCS score was stable among the four different age groups in our study and was not correlated with age. However, the median PCS score was significantly worse in the age group with the oldest patients $(\geq 61$ years) compared to the group with the youngest patients ( $\leq 40$ years). The pattern was similar in the SF-36 Swedish and Norwegian normative population databases displaying associations with age and the physical health domains but small differences for the mental domains across age groups [4, 28].

The multivariable logistic regression analysis in our study revealed that a patient was twice as likely to have a worse PCS score if they lived without a partner, and three times more likely to have a worse PCS score if they had ASDAS-CRP $\geq 2.1$ vs ASDAS-CRP $<2.1$. A longer symptom duration and higher BASFI were also associated with a worse PCS score. Analyses by sex revealed that a high BASFI and ASDAS-CRP were the most important determinants of a worse PCS score in the men, while in the women high BASFI/reduced physical function was associated with a worse PCS score. Salaffi et al. also found that high disease activity and chronic comorbidity were significantly associated with a lower PCS [9], and Özdemir reported inverse correlation between BASDAI, BASFI and most of the SF-36 domains [12]. We found that the pattern was somewhat different for the MCS score. A global fatigue score above the median value was associated with a six-fold increase in the risk of a worse MCS score. Patients living without a partner and patients who had an ASDAS-CRP $\geq 2.1$ were three times more likely to have a worse MCS score. In analyses stratified by sex the same variables were significant in women, while in men, high levels of fatigue, longer education and absence of severe spinal radiographic changes, defined as $\geq 3$ consecutive intervertebral bridges in the cervical spine and/or the lumbar spine were factors associated with worse MCS score. Opposite results on the level of education have previously been reported by some, with a low level of education or $\leq 12$ years of education associated with worse HRQoL [9, 22, 26]. The discrepancy may have to do with our sex-stratified analyses and differences in selection and demographics between studies. We did not find the mSASSS for radiographic changes or the presence of syndesmophytes in the spine to be significant determinants of SF-36 scores, but severe spinal radiographic changes in men, defined as $\geq 3$ consecutive intervertebral bridges in the cervical spine and/or the lumbar spine, were associated with better mental health, with MCS in multivariable analyses and with worse physical health, worse physical health, PCS in univariate but not in multivariable analyses. Importantly, it was only men in our study that had $\geq 3$ consecutive intervertebral bridges in the cervical spine and/or the lumbar spine. Only a few previous studies have addressed if there is a relation between radiographic changes in the spine and HRQoL in AS. A Chinese study conducted in 245 patients with AS found that patients with severe kyphosis had a significantly worse PF domain score compared to patients with milder kyphosis [10]. In a study of 962 patients with AS, Bodur et al. identified weak but significant inverse correlation between the Bath Ankylosing Spondylitis Radiology Index (BASRI) and some of the SF-36 domains (PF, GH and $\mathrm{MH}$ ) [29] similar to findings in a study of 100 patients with AS from Morocco [30]. Weak significant correlation was identified between the BASRI and worse Ankylosing Spondylitis Quality of Life questionnaire (ASQoL) scores in univariate but not in multivariate 
regression analyses in early axial SpA [31]. Conversely, a small study conducted in 36 patients with AS found no significant correlation between the mSASSS and SF-36 scores [32] and Machado et al. did not find significant association between the PCS or MCS scores and the mSASSS [13], while a higher mSASSS was significantly associated with better ASQoL in another study [33]. In a longitudinal study, the mSASSS at baseline was not associated with worse ASQoL over time [34]. In summary, previous results are not consistent, which can be explained by the use of different methods for grading spinal radiographic changes; the mSASSS, BASRI, kyphosis and $\geq 3$ consecutive intervertebral bridges, different questionnaires assessing HRQoL; SF-36 and ASQoL, different statistical approaches; univariate and multivariable analyses and differences in methods of recruiting the patients etc. However, there seems to be some direct association between HRQoL and AS-related spinal radiographic changes. Interestingly, for the first time, to the best of our knowledge, we found that men who had severe spinal radiographic changes had better mental health compared to men without such changes and we hypothesize that it can be explained by adaptive coping strategies in patients with a longstanding chronic disease [35].

The impact on HRQoL of living alone and/or to be unmarried has previously been investigated in other diseases and in the general population, and to the best of our knowledge, for the first time in this study of patients with AS. The literature displays inconsistent results. In patients with chronic diseases such as cancer and multiple sclerosis, living alone is mostly associated with worse HRQoL, which is in line with the findings in our study [36-38]. However, in a longitudinal study, decline in the MCS score in patients with diabetes mellitus was associated with not living alone [39]. In a study from China, participants living alone had worse HRQoL [40], while the opposite was reported from another part of China, Shanghai [41]. Women in the Nurses' Health Study who lived alone had lower risk of decline in the MH and VT domains compared with those living with a spouse. Furthermore, contact with friends and relatives and level of social engagement significantly protected against a decline in $\mathrm{MH}$ in women living alone but not among women living with a partner [42]. Thus, the influence of living alone on HRQoL is complex and seems to be related to the persons' state of health, culture and gender, among other factors.

The sex-stratified analyses in our study revealed some differences; the disease activity seemed to be a more important factor in the physical component of HRQoL in men while the civil state was more important for the mental component of HRQoL in women, which are aspects that can be taken into account in the management of the patients with AS.

There are some limitations to be acknowledged; first this study is cross-sectional and thus we cannot draw any conclusions about the variables identified as associated with worse HRQoL and causality. To investigate this a longitudinal study is required. Second, the SF-36 Swedish normative population database was created in the 1990s and HRQoL in the general population might have changed over the years. However, HRQoL in the general population assessed by the SF-36 was stable from 1996 to 2004 in Norway [43], our neighbouring country, indicating that the difference in time may not be a significant problem. Third, we chose to divide the patients with AS according to their median values of PCS and MCS. Since there is no established cutoff for better or worse HRQoL we used this pragmatic approach. Furthermore, the modest number of subjects in the sex-stratified analyses result in broad confidence intervals and thus results need to be interpreted with some caution. Strengths of this study comprise first, a well-characterised patient cohort with an adequate number of patients allowing subgroup analyses of the sexes to be carried out for the first time. Second, SF-36 scores in patients with AS were compared to those in a large sample of controls from the general population who were precisely matched on sex and age.

Possible implications of our findings include that we have identified variables associated with worse HRQoL, which are modifiable. Even though our study is cross-sectional, and thus not able to show causality, by using these variables as a guide, patients may be treated more efficiently, leading to reduction in disease activity, pain and fatigue, thus potentially improving both the PCS and MCS scores as has been shown in some clinical trials [44-46]. To live alone without a partner was also associated with worse HRQoL in particular in women in the MCS score. A focus on social activities and community support for women with AS might help to improve MCS scores in this subset of patients with AS.

\section{Conclusions}

In this study we show that the patients with AS had significantly lower HRQoL when assessed by the SF-36, compared with the general population. The PCS score was more affected than the MCS score in both sexes. Both demographic and disease-related factors were associated with worse HRQoL, with partial overlap for the PCS and MCS. There were some differences between sexes in the factors associated with HRQoL. By modifying factors such as ASDAS-CRP and fatigue, HRQoL 
may potentially be improved. There is a need for longitudinal studies investigating predictors related to the development of HRQoL in AS over time. We intend to investigate factors related to the change in HRQoL over a 5-year period in this same cohort of patients with AS in a future study.

\section{Additional files}

Additional file 1: Table S1. Results of the SF-36 in patients with ankylosing spondylitis and in controls from the general population. Table S2. Comparisons of variables in patients with ankylosing spondylitis with scores below or above the median PCS score. Table S3. Comparisons of variables in patients with ankylosing and spondylitis scores below or above the median MCS score. Table S4. Univariate logistic regression analyses with PCS score below the median values as dependent variable and all assessed variables as covariates. Table S5. Univariate logistic regression analyses with MCS score below the median values as dependent variable and all assessed variables as covariates. Table S6. Multivariable logistic regression analyses with PCS and MCS scores below their median values as dependent variables and demographics as covariates. (DOCX $92 \mathrm{~kb}$ )

\section{Abbreviations}

AS: Ankylosing spondylitis; ASAS: Assessment of SpondyloArthritis International Society; ASDAS: Ankylosing Spondylitis Disease Activity Score; BASDAl: Bath Ankylosing Spondylitis Disease Activity Index; BASFI: Bath Ankylosing Spondylitis Functional Index; BASG: Bath Ankylosing Spondylitis Patient Global; BASMI: Bath Ankylosing Spondylitis Metrology Index; BASRI: Bath Ankylosing Spondylitis Radiology Index; BMI: Body mass index; BP: Bodily pain; Cl: Confidence interval; CRP: C-reactive protein; DMARD: Disease-modifying anti-rheumatic drug; ESR: Erythrocyte sedimentation rate; GH: General health; HLA-B27: Human leukocyte antigen B27; HRQoL: Health-related quality of life; IBD: Inflammatory bowel disease; MCS: Mental component summary; MH: Mental health; mSASSS: Modified Stoke Ankylosing Spondylitis Spine Score; NSAID: Non-steroid antiinflammatory drug; OR: Odds ratio; PCS: Physical component summary; PF: Physical functioning; RE: Role emotional; RP: Role physical; SD: Standard deviation; SF: Social functioning; SF-36: Short form-36; TNFi: Tumor necrosis factor inhibitor; VAS: Visual analogue scale; VT: Vitality

\section{Acknowledgements}

We wish to thank all the patients who participated in the study.

\section{Funding}

This study was supported by grants from the Health and Medical Care Executive Board of the Västra Götaland, Göteborg's Association Against Rheumatism, Västerbotten's Association Against Rheumatism, The Swedish Research Council, The Swedish Association Against Rheumatism, The Swedish Society of Medicine, The Göteborg Medical Society, the Region Västra Götaland and the County of Västerbotten (agreement concerning research and education of doctors).

\section{Availability of data and materials}

The data sets analysed during the current study are not publicly available due to the Swedish legislation (the Personal Data Act), but a limited and fully anonymised data set that supports the main analyses is available from the corresponding author on request.

\section{Authors' contributions}

$\mathrm{LL}$ and JBR participated in analysis and interpretation of data and drafting the manuscript, $A D$ and EK participated in the design of the study and acquisition, analysis and interpretation of data. LTHJ participated in drafting the manuscript and interpretation of data. HFd'E participated in the conception and design of the work, acquisition, analysis and interpretation of data and drafting the manuscript. All authors critically reviewed the manuscript and approved the final version to be published.

\section{Ethics approval and consent to participate}

The study was approved by the regional ethics committee in Gothenburg, Sweden (reference number Dnr 597-08) and was performed in accordance with the Helsinki declaration. All participants gave their written informed consent.

\section{Consent for publication}

Not applicable.

\section{Competing interests}

LTHJ has received Advisory Board Fees from Novartis, Celgene and MSD, outside the submitted work. HFd'E has received Advisory Board Fees from Sandoz, Novartis and Abbvie outside the submitted work and an unrestricted grant from Novartis. LL, JRB, AD and EK report no competing interests.

\section{Publisher's Note}

Springer Nature remains neutral with regard to jurisdictional claims in published maps and institutional affiliations.

Received: 30 April 2018 Accepted: 3 December 2018

Published online: 27 December 2018

\section{References}

1. Braun J, Sieper J. Ankylosing spondylitis. Lancet. 2007;369(9570):1379-90.

2. Baraliakos X, Listing J, Rudwaleit M, Haibel H, Brandt J, Sieper J, Braun J. Progression of radiographic damage in patients with ankylosing spondylitis: defining the central role of syndesmophytes. Ann Rheum Dis. 2007;66(7): 910-5.

3. Ware JE Jr, Sherbourne CD. The MOS 36-item short-form health survey (SF-36). I. Conceptual framework and item selection. Med Care. 1992; 30(6):473-83.

4. Sullivan M, Karlsson J. The Swedish SF-36 Health Survey III. Evaluation of criterion-based validity: results from normative population. J Clin Epidemiol. 1998;51(11):1105-13.

5. Sullivan M, Karlsson J, Ware JE Jr. The Swedish SF-36 Health Survey-I. Evaluation of data quality, scaling assumptions, reliability and construct validity across general populations in Sweden. Soc Sci Med. 1995;41(10): 1349-58.

6. Persson LO, Karlsson J, Bengtsson C, Steen B, Sullivan M. The Swedish SF-36 Health Survey II. Evaluation of clinical validity: results from population studies of elderly and women in Gothenborg. J Clin Epidemiol. 1998;51(11): 1095-103.

7. Yang X, Fan D, Xia Q, Wang M, Zhang X, Li X, Cai G, Wang L, Xin L, Xu S, et al. The health-related quality of life of ankylosing spondylitis patients assessed by SF-36: a systematic review and meta-analysis. Qual Life Res. 2016:25(11):2711-23.

8. Ribu L, Hanestad BR, Moum T, Birkeland K, Rustoen T. A comparison of the health-related quality of life in patients with diabetic foot ulcers, with a diabetes group and a nondiabetes group from the general population. Qual Life Res. 2007;16(2):179-89.

9. Salaffi F, Carotti M, Gasparini S, Intorcia M, Grassi W. The health-related quality of life in rheumatoid arthritis, ankylosing spondylitis, and psoriatic arthritis: a comparison with a selected sample of healthy people. Health Qual Life Outcomes. 2009;7:25.

10. Huang JC, Qian BP, Qiu Y, Wang B, Yu Y, Zhu ZZ, Hu J, Qu Z. Quality of life and correlation with clinical and radiographic variables in patients with ankylosing spondylitis: a retrospective case series study. BMC Musculoskelet Disord. 2017;18(1):352

11. Vesovic-Potic V, Mustur D, Stanisavljevic D, Ille T, Ille M. Relationship between spinal mobility measures and quality of life in patients with ankylosing spondylitis. Rheumatol Int. 2009;29(8):879-84

12. Ozdemir O. Quality of life in patients with ankylosing spondylitis: relationships with spinal mobility, disease activity and functional status. Rheumatol Int. 2011;31(5):605-10.

13. Machado P, Landewe R, Braun J, Hermann KG, Baraliakos X, Baker D, Hsu B, van der Heijde D. A stratified model for health outcomes in ankylosing spondylitis. Ann Rheum Dis. 2011;70(10):1758-64.

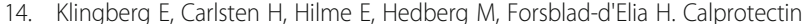
in ankylosing spondylitis-frequently elevated in feces, but normal in serum. Scand J Gastroenterol. 2012;47(4):435-44. https://doi.org/10.3109/00365521. 2011.648953 
15. Lee W, Reveille JD, Davis JC Jr, Learch TJ, Ward MM, Weisman MH. Are there gender differences in severity of ankylosing spondylitis? Results from the PSOAS cohort. Ann Rheum Dis. 2007;66(5):633-8.

16. Klingberg E, Geijer M, Gothlin J, Mellstrom D, Lorentzon M, Hilme E, Hedberg M, Carlsten H, Forsblad-D'Elia H. Vertebral fractures in ankylosing spondylitis are associated with lower bone mineral density in both central and peripheral skeleton. J Rheumatol. 2012;39(10):1987-95.

17. van der Linden S, Valkenburg HA, Cats A. Evaluation of diagnostic criteria for ankylosing spondylitis. A proposal for modification of the New York criteria. Arthritis Rheum. 1984;27(4):361-8.

18. Sieper J, Rudwaleit M, Baraliakos X, Brandt J, Braun J, Burgos-Vargas R, Dougados M, Hermann KG, Landewe R, Maksymowych W, et al. The Assessment of SpondyloArthritis international Society (ASAS) handbook: a guide to assess spondyloarthritis. Ann Rheum Dis. 2009;68(Suppl 2):ii1-44.

19. Machado PM, Landewe R, Heijde DV, Assessment of SpondyloArthritis international S. Ankylosing Spondylitis Disease Activity Score (ASDAS): 2018 update of the nomenclature for disease activity states. Ann Rheum Dis. 2018;77(10):1539-40.

20. Creemers MC, Franssen MJ, van't Hof MA, Gribnau FW, van de Putte LB, van Riel PL. Assessment of outcome in ankylosing spondylitis: an extended radiographic scoring system. Ann Rheum Dis. 2005;64(1):127-9.

21. MacKay K, Mack C, Brophy S, Calin A. The Bath Ankylosing Spondylitis Radiology Index (BASRI): a new, validated approach to disease assessment. Arthritis Rheum. 1998;41(12):2263-70.

22. Dagfinrud $H$, Mengshoel AM, Hagen KB, Loge JH, Kvien TK. Health status of patients with ankylosing spondylitis: a comparison with the general population. Ann Rheum Dis. 2004;63(12):1605-10.

23. Singh JA, Strand V. Spondyloarthritis is associated with poor function and physical health-related quality of life. J Rheumatol. 2009;36(5):1012-20.

24. Davis JC, van der Heijde D, Dougados M, Woolley JM. Reductions in healthrelated quality of life in patients with ankylosing spondylitis and improvements with etanercept therapy. Arthritis Rheum. 2005;53(4):494-501.

25. Klingberg E, Lorentzon M, Mellstrom D, Geijer M, Gothlin J, Hilme E, Hedberg M, Carlsten H, Forsblad-d'Elia H. Osteoporosis in ankylosing spondylitis - prevalence, risk factors and methods of assessment. Arthritis Res Ther. 2012;14(3):R108.

26. Ward MM. Health-related quality of life in ankylosing spondylitis: a survey of 175 patients. Arthritis Care Res. 1999;12(4):247-55.

27. Webers C, Essers I, Ramiro S, Stolwijk C, Landewe R, van der Heijde D, van den Bosch F, Dougados M, van Tubergen A. Gender-attributable differences in outcome of ankylosing spondylitis: long-term results from the Outcome in Ankylosing Spondylitis International Study. Rheumatology (Oxford). 2016; 55(3):419-28.

28. Loge JH, Kaasa S. Short form 36 (SF-36) health survey: normative data from the general Norwegian population. Scand J Soc Med. 1998;26(4):250-8.

29. Bodur H, Ataman S, Rezvani A, Bugdayci DS, Cevik R, Birtane M, Akinci A, Altay Z, Gunaydin R, Yener M, et al. Quality of life and related variables in patients with ankylosing spondylitis. Qual Life Res. 2011;20(4):543-9.

30. Ibn Yacoub Y, Amine B, Laatiris A, Abouqal R, Hajjaj-Hassouni N. Healthrelated quality of life in Moroccan patients with ankylosing spondylitis. Clin Rheumatol. 2011;30(5):673-7.

31. Fernandez-Carballido C, Navarro-Compan V, Castillo-Gallego C, CastroVillegas MC, Collantes-Estevez E, de Miguel E, Esperanza Study G. Disease activity as a major determinant of quality of life and physical function in patients with early axial spondyloarthritis. Arthritis Care Res (Hoboken). 2017; 69(1):150-5

32. Cho $H$, Kim $T$, Kim TH, Lee $\mathrm{S}$, Lee KH. Spinal mobility, vertebral squaring, pulmonary function, pain, fatigue, and quality of life in patients with ankylosing spondylitis. Ann Rehabil Med. 2013;37(5):675-82.

33. Lopez-Medina C, Garrido-Castro JL, Castro-Jimenez J, Gonzalez-Navas C, CalvoGutierrez J, Castro-Villegas MC, Ortega-Castro R, Escudero-Contreras A, FontUgalde P, Collantes-Estevez E. Evaluation of quality of life in patients with axial spondyloarthritis and its association with disease activity, functionality, mobility, and structural damage. Clin Rheumatol. 2018;37(6):1581-8.

34. Essers I, Ramiro S, Stolwijk C, Blaauw M, Landewe R, van der Heijde D, van den Bosch F, Dougados M, van Tubergen A. Do extra-articular manifestations influence outcome in ankylosing spondylitis? 12-year results from OASIS. Clin Exp Rheumatol. 2016;34(2):214-21.

35. Bussing A, Ostermann T, Neugebauer EA, Heusser P. Adaptive coping strategies in patients with chronic pain conditions and their interpretation of disease. BMC Public Health. 2010;10:507.
36. Fernandez O, Baumstarck-Barrau K, Simeoni MC, Auquier P, MusiQo Lsg. Patient characteristics and determinants of quality of life in an international population with multiple sclerosis: assessment using the MusiQoL and SF-36 questionnaires. Mult Scler. 2011;17(10):1238-49.

37. Parker PA, Baile WF, de Moor C, Cohen L. Psychosocial and demographic predictors of quality of life in a large sample of cancer patients. PsychoOncology. 2003;12(2):183-93.

38. Sarna L, Padilla G, Holmes C, Tashkin D, Brecht ML, Evangelista L. Quality of life of long-term survivors of non-small-cell lung cancer. J Clin Oncol. 2002; 20(13):2920-9.

39. Schunk M, Reitmeir P, Ruckert-Eheberg IM, Tamayo T, Schipf S, Meisinger $C$, Peters A, Scheidt-Nave C, Ellert U, Hartwig S, et al. Longitudinal change in health-related quality of life in people with prevalent and incident type 2 diabetes compared to diabetes-free controls. PLoS One. 2017;12(5): e0176895.

40. Rao Y, Xu X, Liu D, Reis C, Newman IM, Qin L, Sharma M, Shen J, Zhao Y. Health-related quality of life in patients with arthritis: a cross-sectional survey among middle-aged adults in Chongqing, China. Int J Environ Res Public Health. 2018;15(4):768.

41. Wang R, Wu C, Zhao Y, Yan X, Ma X, Wu M, Liu W, Gu Z, Zhao J, He J. Health related quality of life measured by SF-36: a population-based study in Shanghai, China. BMC Public Health. 2008:8:292.

42. Michael YL, Berkman LF, Colditz GA, Kawachi I. Living arrangements, socia integration, and change in functional health status. Am J Epidemiol. 2001; 153(2):123-31.

43. Fossa SD, Hess SL, Dahl AA, Hjermstad MJ, Veenstra M. Stability of healthrelated quality of life in the Norwegian general population and impact of chronic morbidity in individuals with and without a cancer diagnosis. Acta Oncol. 2007:46(4):452-61.

44. Morck B, Pullerits R, Geijer M, Bremell T, Forsblad-d'Elia H. Infliximab dose reduction sustains the clinical treatment effect in active HLAB27 positive ankylosing spondylitis: a two-year pilot study. Mediat Inflamm. 2013;2013: 289845.

45. Revicki DA, Luo MP, Wordsworth P, Wong RL, Chen N, Davis JC Jr, Group AS. Adalimumab reduces pain, fatigue, and stiffness in patients with ankylosing spondylitis: results from the adalimumab trial evaluating longterm safety and efficacy for ankylosing spondylitis (ATLAS). J Rheumatol. 2008;35(7):1346-53.

46. Deodhar AA, Dougados M, Baeten DL, Cheng-Chung Wei J, Geusens P, Readie A, Richards HB, Martin R, Porter B. Effect of secukinumab on patientreported outcomes in patients with active ankylosing spondylitis: a phase III randomized trial (MEASURE 1). Arthritis Rheumatol. 2016;68(12):2901-10.

Ready to submit your research? Choose BMC and benefit from:

- fast, convenient online submission

- thorough peer review by experienced researchers in your field

- rapid publication on acceptance

- support for research data, including large and complex data types

- gold Open Access which fosters wider collaboration and increased citations

- maximum visibility for your research: over $100 \mathrm{M}$ website views per year

At $\mathrm{BMC}$, research is always in progress.

Learn more biomedcentral.com/submissions 